\title{
PENGEMBANGAN LEMBAR KERJA SISWA (LKS) BERBASIS PROBLEM BASED LEARNING (PBL) PADA MATERI MATRIKS SISWA KELAS XI MIA SMAN 6 KOTA JAMBI
}

\author{
Yeni Purwati ${ }^{16}$, \\ Buyung $^{17}$, Relawati ${ }^{18}$
}

\begin{abstract}
This study aims to develop LKS and knowing the quality of the LKS developed in the aspect of validity, practicality, and effectiveness. The development of this LKS done on the material matrix of Class XI MIA SMAN 6 city of Jambi. This type of research is the development of research or Research \& Developmet $(R \& D)$. This study refers to the ADDIE (Analysis, Design, Development or Production, Implementation or Delivery and Evaluations). Assessment instruments used in this development is LKS by expert validation sheet material, design experts, media experts, the evaluation sheet, pre-test and post test. The quality of LKS onaspects of validity views based on validation by experts that is meets the criteria is very good and very viable with overall average 4.14 as well as the overall percentage of $82.9 \%$. On the practicality of views based on the results of the evaluation of field trials by students that is meet the criteria of good and viable with average 4.00 sera overall percentage of $81 \%$. While on the effectiveness of views based on a calculation t count $\left(t_{h}\right)$ from the results of pretest and post-test earned amounting to 23.39 and t table $\left(t_{t}\right)$ of 2.02 so $t_{h}$ greater than $t_{t}$. This shows that the hypothesis was accepted and acknowledged there were significant differences between the pre-test and post-test. Calculation based on the development of LKS based PBL was declared effective.
\end{abstract}

Keywords: Student Worksheet (LKS), Matrix, Development, Problem Based Learning $(P B L)$.

\footnotetext{
${ }^{16}$ Mahasiswa Program Studi Pendidikan Matematika Universitas Batanghari

${ }^{17}$ Dosen Program Studi Pendidikan Matematika Universitas Batanghari

${ }^{18}$ Dosen Program Studi Pendidikan Matematika Universitas Batanghari
} 


\section{PENDAHULUAN}

Matematika merupakan ilmu dasar utama yang sudah diperkenalkan sejak berada di jenjang sekolah dasar sampai sekolah menengah. Tujuan pendidikan matematika pada jenjang sekolah menengah menekankan pada penerapan di kehidupan sehari-hari. Proses pembelajaran inovatif dan menarik perlu diterapkan oleh guru melalui bahan ajar. Salah satu jenis bahan ajar untuk mengefektifkan proses pembelajaran adalah Lembar Kerja Siswa (LKS). Lembar Kerja Siswa (LKS) merupakan suatu bahan ajar cetak berupa lembaran-lembaran kertas yang berisi materi, ringkasan, dan petunjuk-petunjuk pelaksanaan tugas pembelajaran yang harus dikerjakan oleh peserta didik yang mengacu pada kompetensi dasar yang harus dicapai (Prastowo, 2011:204).

Kurikulum 2013 yang digunakan saat ini memuat seluruh KD yang mengaitkan semua materi ke konteks nyata. Hal ini tentu menuntut siswa untuk dapat memahami materi, mengaitkan materi ke konteks nyata dan memecahkan masalah terkait kehidupan sehari-hari. LKS yang digunakan pun harus mengacu pada KD yang harus dicapai. Sedangkan LKS yang dibeli dari penerbit, tidak semua materi mengaitkan pada konteks nyata. LKS seperti tersebut di atas tentu belum dapat memenuhi Kompetensi Dasar (KD) yang akan dicapai pada kurikulum 2013. Sehingga dibutuhkan LKS yang dapat mengarahkan siswa untuk memecahkan masalah yang berkaitan dengan kehidupan sehari-hari.

Pengembangan LKS harus didasarkan pada pembelajaran yang tepat. Pembelajaran dengan melibatkan siswa untuk memecahkan masalah melalui tahap-tahap metode ilmiah salah satunya adalah Problem Based Learning (PBL). Moffit (depdiknas, 2002:12) mengemukakan bahwa Problem Based Learning (PBL) merupakan suatu pembelajaran yang menggunakan masalah dunia nyata sebagai suatu konteks bagi siswa untuk melatih keterampilan pemecahan masalah dan untuk memperoleh pengetahuan dan konsep yang esensi dari materi pelajaran. Problem Based Learning (PBL) dapat mengoptimalisasi kemampuan berpikir siswa dengan berorientasi pada masalah kehidupan sehari-hari melalui proses kerja individu, kelompok atau tim yang sistematis untuk melatih keterampilan pemecahan masalah dan memperoleh pengetahuan dan konsep.

Pengembangan bahan ajar berupa Lembar Kerja Siswa (LKS) berbasis Problem Based Learning (PBL) ini dilakukan pada materi Matriks. Matriks merupakan materi yang mengandung berbagai konsep dan prinsip-prinsip dalam pengoperasiannya. Secara khusus keterkaitan kosep dan prinsip-prinsip matriks dengan permasalahan nyata, bersumber dari fakta dan lingkungan budaya. Sehingga konsep matriks dapat dibangun atau ditemukan di dalam penyelesaian permasalahan sehari-hari.

LKS berbasis Problem Based Learning (PBL) ini menyajikan fase pemecahan masalah yang akan membantu siswa mengorganisasi informasi-informasi untuk dihubungkan dengan konsep sehingga 
siswa memiliki keterampilan untuk memecahkan masalah.

Ibrahim, Ismail, dan Nur (Rusman, 2014:243) mengemukakan 5 fase PBL yang terdapat di dalam LKS.

a. Fase 1: Orientasi siswa terhadap Masalah

Pada tahap ini, siswa disajikan dengan suatu peristiwa nyata di kehidupan sehari-hari yang akan menjadi permasalahan untuk diselesaikan.

b. Fase 2: Mengorganisasikan siswa untuk belajar

Pada tahap ini, siswa diarahkan untuk memahami masalah yaitu dengan menuliskan informasi yang diketahui dari permasalahan dan menentukan rumusan masalah.

c. Fase 3: Membimbing pengalaman individual/kelompok Pada tahap ini, siswa dibimbing mengenai cara menyelesaikan permasalahan yang disajikan secara individual/kelompok.

d. Fase 4: Mengembangkan dan menyajikan hasil karya

Pada tahap ini, siswa diarahkan untuk menuliskan poin-poin penting tentang pemecahan masalah mulai dari memahami masalah sampai dengan cara menyelesaikan masalah.

e. Fase 5: Menganalisis dan mengevaluasi proses pemecahan masalah

Pada tahap ini, siswa diarahkan untuk menuliskan kembali langkah-langkah pemecahan masalah dan kesimpulan hasil akhir yang diperoleh.

Lembar Kerja Siswa (LKS) berbasis Problem Based Learning
(PBL) ini berhubungan dengan menstimulus kemampuan pemecahan masalah sehingga siswa terlibat aktif dalam kegiatan pembelajaran. Serta dalam usaha memperkaya pengalaman dan membangun pengetahuan dari materi yang dipelajari dalam diri siswa. Adapun tujuan dari penelitian ini adalah mengembangkan Lembar Kerja Siswa (LKS) berbasis Problem Based Learning (PBL) pada materi matriks untuk siswa kelas XI MIA.

\section{METODE PENELITIAN}

Jenis penelitian yang digunakan adalah jenis penelitian pengembangan atau Research\&Developmet (R\&D). Menurut Sugiyono (2015:407), metode penelitian dan pengembangan atau dalam bahasa inggrisnya Research and Development (R\&D) adalah metode penelitian yang digunakan untuk menghasilkan produk tertentu dan menguji keefektifan produk tersebut. Penelitian ini menghasilkan produk berupa bahan ajar berupa Lembar Kerja Siswa (LKS) yang berbasis Problem Based Learning (PBL) pada materi Matriks untuk siswa kelas XI MIA SMAN 6 Kota Jambi. Pengembangan LKS berbasis Problem Based Learning (PBL) ini dilakukan dengan mengacu pada model pengembangan ADDIE (Analysis, Design, Development or Production, Implementation or Delivery and Evaluations).

Pada tahap analisis, peneliti melakukan 3 tahap kegiatan yaitu analisis kurikulum, analisis karakteristik siswa, dan analisis materi. Analisis kurikulum dilakukan dengan mencari informasi mengenai 
kurikulum yang digunakan di sekolah, kompetensi inti (KI), kompetensi dasar (KD), dan materimateri yang ada pada mata pelajaran matematika. Analisis karakteristik siswa dilakukan dengan mencari informasi dari guru mata pelajaran matematika kelas XI tentang pengetahuan dan kemampuan yang dimiliki siswa. Analisis materi dilakukan dengan membahas gambaran secara keseluruhan tentang materi matriks yang kemudian akan disusun secara sistematis di dalam LKS yang dikembangkan. Penyususnan materi ini berdasarkan pada KD dan Indikator.

Pada tahap perancangan, peneliti mulai untuk merancang LKS berbasis Problem Based Learning (PBL) pada materi matriks siswa kelas XI. Adapun rancangan yang dilakukan pada tahapan ini adalah merancang cover LKS, merancang isi LKS dan merancang instrumen penilaian LKS. Pada tahap pengembangan, peneliti melakukan 3 langkah kegiatan yaitu
(1) pembuatan produk LKS; (2) validasi LKS oleh ahli materi, ahli desain dan ahli media; (3) revisi LKS berdasarkan komentar dan saran dari validator. Validasi LKS dilakukan untuk melihat kualitas LKS pada aspek kevalidan.

Setelah LKS dinyatakan valid maka akan diuji cobakan dalam kegiatan pembelajaran. Tahap ini meliputi tahap uji coba LKS yaitu uji coba perorangan, uji coba kelompok kecil dan uji coba lapangan yang dilaksanakan di SMAN 6 Kota Jambi. Uji coba dilakukan dalam 3 kali pertemuan. Pada tahap ini diperoleh data evaluasi uji coba perorangan, evaluasi uji coba kelompok kecil, dan evaluasi uji coba lapangan. Hasil dari uji coba lapangan akan digunakan untuk melihat kualitas LKS pada aspek kepraktisan. Selain itu, jumlah rerata skor tiap aspek pada lembar validasi dan evaluasi dapat diinterpretasikan secara kualitatif dengan rumus sebagai berikut

Tabel 1. Kriteria pengkategorian

\begin{tabular}{|c|c|c|}
\hline Rumus & Rerata Skor & Kriteria \\
\hline$X>\bar{X}_{i}+(1.8) \times s b_{i}$ & $X>4.2$ & Sangat Baik \\
\hline $\bar{X}_{i}+(0.6) \times s b_{i}<X \leq \bar{X}_{i}+(1.8) \times s b_{i}$ & $4.2>X \geq 3.4$ & Baik \\
\hline $\bar{X}_{i}-(0.6) \times s b_{i}<X \leq \bar{X}_{i}+(0.6) \times s b_{i}$ & $3.4>X \geq 2.6$ & Cukup \\
\hline $\bar{X}_{i}-(1.8) \times s b_{i}<X \leq \bar{X}_{i}-(0.6) \times s b_{i}$ & $2.6>X \geq 1.75$ & Kurang \\
\hline$X \leq \bar{X}_{i}-(1.8) \times s b_{i}$ & $X \leq 1.8$ & Kurang Sekali \\
\hline
\end{tabular}

Tabel 2. Kriteria kelayakan

\begin{tabular}{|c|c|c|}
\hline \multicolumn{1}{|l|}{ No } & Interval & Kriteria \\
\hline 1 & $81 \%-100 \%$ & Sangat Layak \\
\hline 2 & $61 \%-80 \%$ & Layak \\
\hline 3 & $41 \%-60 \%$ & Kurang Layak \\
\hline 4 & $21 \%-40 \%$ & Tidak Layak \\
\hline 5 & $0 \%-20 \%$ & Sangat Tidak Layak \\
\hline
\end{tabular}

Tahap terakhir yaitu tahap melakukan 2 evaluasi yaitu evaluasi evaluasi. Pada tahap ini peneliti formatif dan evaluasi sumatif. 
Evaluasi formatif dilakukan berdasarkan data hasil validasi LKS oleh ahli materi, hasil validasi oleh ahli desain, hasil validasi oleh ahli media, hasil evaluasi uji coba perorangan, hasil evaluasi uji coba kelompok kecil, dan hasil evaluasi uji coba lapangan. Berdasarkan rekapitulasi hasil data tersebut, LKS yang dikembangkan dinyatakan layak sebagai perangkat pembelajaran. Sedangkan evaluasi sumatif dilakukan dengan memberikan posttest (tes hasil belajar) siswa setelah melakukan kegiatan pembelajaran menggunakan LKS berbasis PBL ini.

Hasil pre-test yang telah diperoleh pada saat tahap implementasi dan hasil post-test yang diperoleh pada saat tahap evaluasi sumatif kemudian akan dihitung perbedaannya. Perhitungan ini menggunakan rumus uji $\mathrm{t}$ untuk melihat perbedaan signifikan diantara keduanya. Dengan hipotesis jika $t_{\text {hitung }}>t_{\text {tabel }}$ maka pengembangan LKS berbasis PBL dikategorikan efektif dan jika $t_{\text {hitung }}<t_{\text {tabel }}$ maka pengembangan LKS berbasis PBL dikategorikan tidak efektif.

\section{HASIL DAN PEMBAHASAN}

Hasil dari penelitian pengembangan ini adalah berupa Lembar Kerja Siswa (LKS) Berbasis Problem Based Learning (PBL) pada materi matriks kelas XI MIA SMAN 6 Kota Jambi. Kualitas LKS ini memiliki standar kelayakan yang dilihat pada aspek kevalidan LKS, aspek kepraktisan LKS dan aspek keefektifan penggunaan LKS. Aspek kevalidan LKS dilihat dari hasil validasi oleh para ahli yaitu ahli materi, ahli desain, dan ahli media.
Rekapitulasi hasil validasi LKS oleh ahli materi didapat total nilai 42 dengan rata-rata 3,82 dan bila dipersentasekan diperoleh 76,4\% sehingga termasuk kategori baik dan sangat valid sebagai perangkat pembelajaran. Berdasarkan hasil validasi tersebut maka kualitas LKS ini dari segi materi dinyatakan valid. Selanjutnya rekapitulasi hasil validasi LKS oleh ahli desain didapat total nilai 57 dengan rata-rata 4,1 dan bila dipersentasekan diperoleh $81,4 \%$ sehingga termasuk kategori baik dan sangat layak sebagai perangkat pembelajaran. Berdasarkan hasil validasi tersebut maka kualitas LKS ini dari segi desain dinyatakan valid.

Terakhir rekapitulasi hasil validasi LKS oleh ahli media didapat total nilai 50 dengan rata-rata 4,5 dan bila dipersentasekan diperoleh $90,9 \%$ sehingga termasuk kategori sangat baik dan sangat layak sebagai perangkat pembelajaran. Berdasarkan hasil validasi tersebut maka kualitas LKS ini dari segi media dinyatakan valid. Kualitas LKS pada aspek kevalidan dilihat berdasarkan hasil validasi ahli materi, ahli desain, dan ahli media. Hasil validasi oleh para ahli tersebut menunjukkan bahwa LKS berbasis PBL ini berada pada kategori layak, sangat layak dengan persentase $76,4 \%, 81,4 \%$, dan 90,9\%. Berdasarkan rekapitulasi hasil validasi oleh ahli materi, ahli desain, dan ahli media tersebut di atas maka pengembangan LKS berbasis PBL ini dinyatakan valid.Revisi-revisi yang dilakukan pada LKS berdasarkan komentar dan saran dari ahli materi, ahli desain dan ahli media dapat dilihat pada tabel 3 berikut ini. 
Tabel 3. Hasil validasi oleh para ahli berupa komentar dan saran

\begin{tabular}{|c|c|}
\hline Komentar & Saran \\
\hline \multicolumn{2}{|c|}{ Ahli Materi } \\
\hline $\begin{array}{l}\text { Pada kata pengantar dituliskan saran dan } \\
\text { kritik dengan terbuka penulis terima, } \\
\text { namun tidak ada alamat yang bisa dituju } \\
\text { untuk mengirimkan kritik dan saran. }\end{array}$ & $\begin{array}{l}\text { Sebaiknya cantumkan alamat yang } \\
\text { bisa dituju untuk mengirimkan kritik } \\
\text { dan saran }\end{array}$ \\
\hline $\begin{array}{l}\text { Pada daftar isi jika dibuat materi } 1,2,3 \\
\text { maka akan terkesan memisah-misahkan } \\
\text { materi. }\end{array}$ & Cukup buat a, b dan c saja. \\
\hline $\begin{array}{l}\text { Pada daftar isi, jika ditulis bentuk dan } \\
\text { unsur matriks maka nanti ditakutkan } \\
\text { siswa hanya akan mengenal bentuk } \\
\text { matriks seperti yang ada di LKS }\end{array}$ & $\begin{array}{l}\text { Sebaiknya bentuk dan unsur matriks } \\
\text { diganti sesuai dengan yang ada di } \\
\text { LKS pedoman }\end{array}$ \\
\hline $\begin{array}{l}\text { Pada peta konsep alurnya sedikit } \\
\text { membingungkan karena ada cabang- } \\
\text { cabangnya }\end{array}$ & $\begin{array}{l}\text { Sebaiknya buat alur yang lebih } \\
\text { sederhana }\end{array}$ \\
\hline $\begin{array}{l}\text { Materi untuk KD } 4.2 \text { belum ada di dalam } \\
\text { LKS }\end{array}$ & $\begin{array}{l}\text { Buat soal kompleks yang memenuhi } \\
\text { KD } 4.2 \text { tentang memadukan } \\
\text { determinan dan invers }\end{array}$ \\
\hline \multicolumn{2}{|c|}{$\begin{array}{c}\text { Ahli Desain } \\
\end{array}$} \\
\hline $\begin{array}{l}\text { Pada cover LKS gambar yang ada tidak } \\
\text { berhubungan dengan matriks }\end{array}$ & $\begin{array}{l}\text { Pilih gambar cover } \\
\text { berhubungan dengan matriks }\end{array}$ \\
\hline $\begin{array}{l}\text { Isi pada LKS belum mengarahkan siswa } \\
\text { untuk memecahkan masalah }\end{array}$ & $\begin{array}{l}\text { Pada isi LKS bimbinglah siswa untuk } \\
\text { menyelesaikan masalah dan arahkan } \\
\text { siswa untuk menemukan konsep } \\
\text { materi }\end{array}$ \\
\hline \multicolumn{2}{|c|}{$\begin{array}{c}\text { Ahli Media } \\
\end{array}$} \\
\hline $\begin{array}{l}\text { Tulisan sebelah kanan terlalu mepet } \\
\text { dengan bingkai }\end{array}$ & $\begin{array}{l}\text { Sebaiknya margin sebelah kanan } \\
\text { agak digeser kekiri sehingga terlihat } \\
\text { lebih rapi dan tidak penuh }\end{array}$ \\
\hline $\begin{array}{l}\text { Bingkai terlalu mepet ke bagian kiri } \\
\text { kertas }\end{array}$ & $\begin{array}{l}\text { Sebaiknya ukuran margin sebelah } \\
\text { kiriditambah agar nanti LKS nya bisa } \\
\text { dijilid dan bingkainya tidak tertutup }\end{array}$ \\
\hline
\end{tabular}

Aspek kepraktisan LKS dilihat dari hasil evaluasi uji coba perorangan, uji coba kelompok kecil, dan uji coba lapangan.Rekapitulasi hasil evaluasi LKS pada uji coba perorangan oleh 3 orang siswa kelas XI didapat total rata-rata 3,91 dan bila dipersentasekan diperoleh $78 \%$ sehingga termasuk kategori baik dan layak sebagai perangkat pembelajaran. Rekapitulasi hasil evaluasi LKS pada uji coba kelompok kecil oleh 6 orang siswa kelas XI didapat total rata-rata 3,87 dan bila dipersentasekan diperoleh $77 \%$ sehingga termasuk kategori baik dan layak sebagai perangkat pembelajaran. Rekapitulasi hasil evaluasi LKS pada uji coba lapangan oleh 40 orang siswa kelas XI MIA 3 didapat total rata-rata 4.00 dan bila dipersentasekan diperoleh $81 \%$ sehingga termasuk kategori baik dan layak sebagai perangkat pembelajaran. Berdasarkan hasil evaluasi uji coba lapangan tersebut maka LKS ini dinyatakan praktis. 
Keefektifan LKS dilihat saat tahap evaluasi sumatif. Evaluasi ini dilakukan dengan memberikan posttest setelah melakukan kegiatan pembelajaran dengan menggunakan LKS yang telah dikembangkan. Hasil dari pre-test yang telah dilakukan, diperoleh bahwa 40 orang siswa kelas XI MIA 3 tersebut dinyatakan tidak tuntas. Sedangkan hasil dari post-test yaitu setelah siswa dibelajarkan menggunakan LKS diperoleh 23 siswa tuntas dengan nilai mencapai KKM dan 17siswa tidak tuntas dengan nilai di bawah KKM.
Subjek penelitian dinyatakan berdistribusi normal dengan L hitung sebesar 0,1394 dan $\mathrm{L}$ tabel sebesar 0,1401 sehingga $L_{h}<L_{t}$. Sedangkan perhitungan $\mathrm{t}$ hitung $\left(\mathrm{t}_{\mathrm{h}}\right)$ dari hasil pre-test dan post-test diperoleh sebesar 23,39 dan $t$ tabel $\left(t_{t}\right)$ sebesar 2,02 sehingga $t_{h}>\quad t_{t}$.Hal ini menunjukkan bahwa hipotesis diterima dan dinyatakan ada perbedaan signifikan antara pre-test dan post-test. Berdasarkan perhitungan tersebut maka pengembangan LKS berbasis PBL ini dinyatakan efektif.

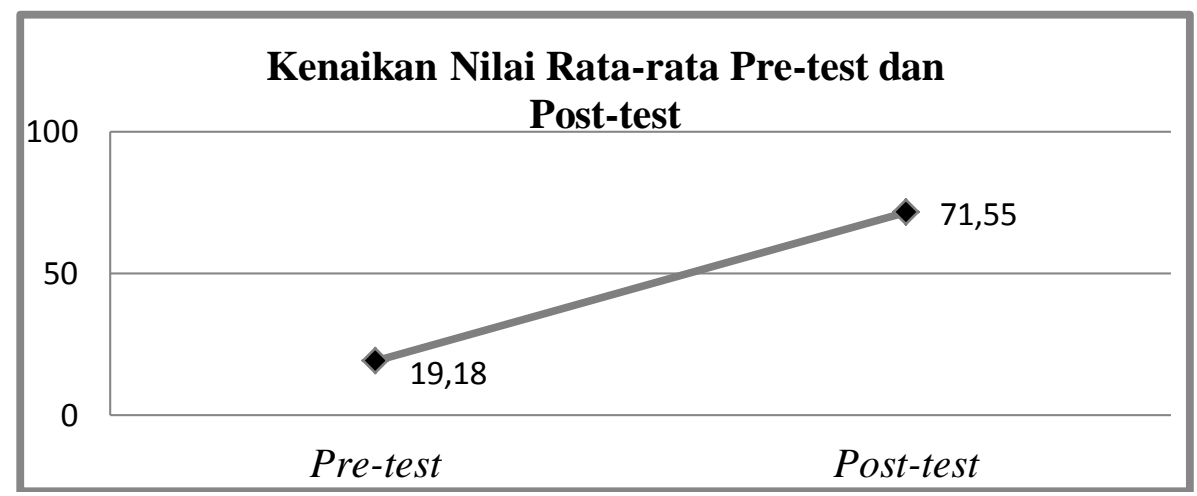

\section{Diagram 1. Garis kenaikan nilai rata-rata pre-test dan post-test}

Terdapat beberapa keterbatasan penelitian pengembangan LKS berbasis PBL ini antara lain:

1. LKS berbasis PBL yang dikembangkan hanya mencakup satu materi saja yaitu materi matriks.

2. LKS berbasis PBL yang dikembangkan merupakan pengembangan tingkat pemula.

3. Implementasi LKS hanya dilakukan pada satu kelas pada satu sekolah yaitu SMAN 6 Kota Jambi.
4. Dana pengeluaran pada penelitian pengembangan LKS berbasis PBL ini cukup besar.

5. Waktu yang digunakan pada penelitian ini sangat terbatas.

\section{SIMPULAN}

Lembar Kerja Siswa (LKS) yang dikembangkan berupa lembaranlembaran kertas yang berisi materi, ringkasan dan petunjuk pelaksanaan tugas pembelajaran yang dikerjakan oleh siswa dengan mengacu pada kompetensi dasar yang harus dicapai sehingga muncul sifat kemandirian belajar pada diri siswa. LKS yang 
dikembangkan merupakan jenis LKS terstruktur yang memiliki urutan yang terstruktur dengan baik yang terdiri dari judul materi,kata pengantar, daftar isi, petunjuk penggunaan LKS, kompetensi dasar, indikator, peta konsep, tugas-tugas dan latihan, penilaian dan daftar pustaka.Penyajian isi LKS yaitu diberikan masalah kemudian memecahan masalah menggunakan fase PBL, tugas individu dan kelompok, dan uji kompetensi siswa bersifat pemecahan masalah yang berkaitan dengan masalah kehidupan sehari-hari. Sesuai dengan definisi PBL menurut Darmadi (2017:117) Problem Based Learning (PBL) adalah suatu metode pembelajaran yang menantang peserta didik untuk belajar bagaimana belajar, bekerja secara berkelompok untuk mencari solusi dari permasalahan dunia nyata.

Hasil validasi oleh para ahli tersebut menunjukkan bahwa LKS berbasis PBL ini berada pada kategori layak, sangat layak dengan persentase $76,4 \%, 81,4 \%$, dan $90,9 \%$. Berdasarkan perhitungan tersebut maka pengembangan LKS berbasis PBL ini dinyatakan valid.LKS berbasis PBL ini mendapat persentase nilai sebesar $80 \%$ pada uji coba lapangan. Berdasarkan perhitungan tersebut maka pengembangan LKS berbasis PBL ini dinyatakan praktis. Perhitungan $\mathrm{t}$ hitung $(\mathrm{t})$ dari hasil pretest dan post-test diperoleh sebesar 20,60 dan $\mathrm{t}$ tabel $\left(\mathrm{t}_{0}\right)$ sebesar 2,02 sehingga $\mathrm{t}>\mathrm{t}_{0}$. Hal ini menunjukkan bahwa hipotesis diterima dan dinyatakan ada perbedaan signifikan antara pre-test dan post-test. Berdasarkan perhitungan tersebut maka pengembangan LKS berbasis PBL ini dinyatakan efektif.

Manfaat dari LKS ini yaitu dapatdisumbangan kepada sekolah berupa bahan ajar cetak yaitu Lembar Kerja Siswa (LKS) Berbasis Problem Based Learning (PBL) pada materi Matriks untuk siswa SMA kelas XI guna meningkatkan kualitas pembelajaran matematika.Dapat dijadikan sebagai salah satu sumber bahan serta memotivasi guru dalam mengembangkan bahan ajar lainnya sebagai bahan pembelajaran matematika. Dapat meningkatkan aktivitas siswa dalam belajar serta mempermudah siswa memahami konsep matematika dan bekerja sama dengan siswa yang lain melalui kegiatan pembelajaran yang ada pada Lembar Kerja Siswa (LKS). Serta dapat menambah wawasan dan acuan untuk mengembangkan bahan ajar berupa Lembar Kerja Siswa (LKS) Matematika Berbasis Problem Based Learning (PBL).

Berdasarkan kelayakan dan keterbatasan penelitian yang telah dibahas sebelumnya, peneliti menyarankan LKS berbasis PBL ini perlu dikembangkan lagi dalam hal materi agar tidak hanya memuat materi matriks saja tetapi memuat materi-materi lain.Pada penelitian selanjutnya, sebaiknya pengimplementasian LKS yang dikembangkan tidak hanya di satu sekolah atau satu kelas saja, namun lebih dari satu sekolah dan satu kelas agar pemanfaatan LKS yang dikembangkan dapat digunakan secara luas.Pada penelitian pengembangan selanjutnya, diharapkan dapat mengembangkan Lembar Kerja Siswa (LKS) 
Matematika dengan variasi-variasi yang lain guna menghasilkan produk LKS yang lebih baik dan lebih menarik lagi.

\section{DAFTAR PUSTAKA}

Darmadi. 2017. Pengembangan Model dan Metode Pembelajaran dalam Dinamika Belajar Siswa. Yogyakarta: Deepublish

Depdiknas. 2008. Panduan Pengembangan Bahan Ajar. Jakarta: Departemen Pendidikan Nasional Direktorat Pendidikan Dasar dan Menengah.

Prastowo, Andi. 2011. Panduan Kreatif membuat Bahan Ajar Inovatif. Yogyakarta: DIVA Press.

Rusman. 2014. Model-Model Pembelajaran Edisi Kedua. Jakarta: PT. Raja Grafindo Persada.

Supardi. 2014. Aplikasi Statistika dalam Penelitian. Jakarta Selatan: Change Publication.

Widoyoko, 2015. Evaluasi Program Pembelajaran. Yogyakarta: Pustaka Pelajar. 